BMJ Open Sport \& Exercise Medicine

\title{
Do static and dynamic activities induce potentially damaging breast skin strain?
}

\author{
Michelle Norris, ${ }^{1,2,3}$ Chris Mills (D) , ${ }^{3}$ Amy Sanchez, ${ }^{3}$ Joanna Wakefield-Scurr ${ }^{3}$
}

To cite: Norris M, Mills $C$, Sanchez A, et al. Do static and dynamic activities induce potentially damaging breast skin strain? BMJ Open Sport \& Exercise Medicine 2020;6:e000770. doi:10.1136/ bmjsem-2020-000770

- Additional material is published online only. To view please visit the journal online (http://dx.doi.org/10.1136/ bmjsem-2020-000770).

Accepted 11 June 2020

\section{Check for updates}

\section{(C) Author(s) (or their} employer(s)) 2020. Re-use permitted under CC BY-NC. No commercial re-use. See rights and permissions. Published by BMJ.

${ }^{1}$ Lero, the Irish Software Research Centre, University of Limerick, Limerick, Ireland ${ }^{2}$ Health Research Institute (HRI), University of Limerick, Ageing Research Centre (ARC), Limerick, Ireland

${ }^{3}$ School of Sport, Health and Exercise Science, University of Portsmouth, Portsmouth, UK

Correspondence to Dr Chris Mills; chris.mills@port.ac.uk

\section{ABSTRACT}

Background/Aim This study aimed to quantify breast skin strain and strain rate and the effect of support garments at reducing strain and to determine characteristics that correlate with strain during static and dynamic activity.

Methods 39 women (UK size $32 \mathrm{C}$ to $36 \mathrm{G}$ ) had electromagnetic sensors applied to their breast skin. Sensor coordinates were recorded while standing, walking, running, in no, low and high breast support conditions, plus bare-breasted in the estimated neutral position to calculate strain. Relative breast coordinates and 35 intersensor distances identified peak breast skin strain (\%) and strain rate $\left(\% \cdot \mathrm{s}^{-1}\right)$, which were then correlated with nipple kinematics, breast pain and participant characteristics. Results Mean peak breast skin strain was generally $<60 \%$ during standing, walking and running; however, some individuals exhibited $93 \%$ strain in bare-breasted running. Compared with low support, high support did not further reduce strain during standing and walking. Peak breast skin strain/strain rate location was longitudinal, in lateral and medial breast regions and displayed strong correlations with breast volume, body mass index and bust circumference.

Conclusion Static and dynamic activity did not result in excessive breast skin strain, suggesting low risk of skin damage. However, during running, some individuals experienced excessive skin strains (up to 93\%) and strain rates (up to $1258 \% \cdot \mathrm{s}^{-1}$ ). Breast skin strain/strain rate location suggests lift is required in the lateral and medial bra cup to reduce strain, particularly in larger breast volumes due to increased skin strain risk.

\section{INTRODUCTION}

The unsupported breast moves independently during dynamic activities. ${ }^{1-3}$ This independent movement is thought to be driven by torso displacement ${ }^{45}$ and occurs due to limited anatomical support within the breast. ${ }^{4}$ This limited supported is provided by Cooper's ligaments and breast skin. ${ }^{6}$ Previous research has reported that the bare breast is vertically displaced $\sim 4 \mathrm{~cm}$ during walking ${ }^{78}$ and up to $10 \mathrm{~cm}$ during running. ${ }^{1-389}$ While external breast support garments decrease movement $(\sim 6 \mathrm{~cm}$ decrease in vertical displacement during running), ${ }^{10}$ movement-related breast pain is still common during exercise in inadequate support garments. 491112

\section{What are the new findings}

Generally, women do not experience damaging peak breast skin strains (>60\%) during standing, walking and running, regardless of breast support level. However, some individuals may exhibit damaging breast skin strains of up to $93 \%$ strain during barebreasted running.

- Lateral and medial breast regions are more susceptible to peak breast skin strain and strain rates, with these commonly occurring longitudinally.

- Women with greater breast volumes, body mass indices and bust circumferences may be more susceptible to damaging their breast skin due to increased peak breast skin strains and strain rates.

The aetiology of movement-related breast pain is unclear, but associations with strain on breast support structures have been suggested. ${ }^{9} 13$ When measuring strain, assessment of the Cooper's ligaments during dynamic activity may not always be possible due to their internal location. ${ }^{14} 15$ However, the measurement of breast skin strain is important as breast ptosis (sag) may be related to mechanical strain on breast skin, with mechanical failure of skin possibly manifesting in stretch marks (striae distensae). ${ }^{1617}$

Measuring strain in the body determines the magnitude and reversibility of biological tissue's response to external loading. ${ }^{18-22}$ Skin displays a non-linear, time-dependent stressstrain relationship. ${ }^{23} 24$ Skin's stress-strain curve is divided into four phases ${ }^{25}$ : phase 1 (<30\% skin strain), straightening of collagen fibres; phases 2 and $3(30 \%$ and $60 \%$ skin strain), realignment of fibres in the direction of stress, collagen begins to resist deformation; phase 4 (>60\% skin strain), collagen fibres begin to fracture. ${ }^{25}{ }^{26}$ It is this collagen failure (occurring due to defibrillation) that signifies skin damage. $^{27}$

In healthy breast skin samples, Kumaraswamy et $a l^{28}$ identified up to $58 \%$ strain without fibril damage. However, strain assessment was performed in vitro using a testing rig restricted to $58 \%$ strain. It is therefore unknown if an increase in strain 
above $58 \%$ would result in skin damage. Haake and Scurr ${ }^{29}$ and Haake $e t a l^{30}$ investigated breast skin strain in vivo during bare-breasted running reporting strains of up to $\sim 120 \%$. However, strain was calculated uniaxially, between the sternal notch and nipple, rather than across the breast surface. Sanchez $e t a l^{31}$ used an 18-marker array across the breast surface to identify breast skin strain during standing. Breast skin strain of $75 \%$ in longitudinal superior and lateral breast regions were reported, providing data on strain magnitudes, locations and directions. ${ }^{31}$ While this study advanced in-vivo breast skin strain measurement, marker coordinates on the bare breast were recorded by motion capture cameras which could not determine skin strain inside a bra.

The limited studies that measure breast skin strain have focused on strain magnitude; strain rate has yet to be considered in vivo despite associations between skin strain rate, ultimate tensile strength of skin and pain sensation. ${ }^{33}$ Using pig skin, which displays similar mechanics to human skin, ${ }^{34}$ Liu $e t a l^{33}$ reported reduced pain at low skin strain rates, but sharp increases in pain as strain rate increased. ${ }^{33}$ Therefore, understanding relationships between breast skin strain rate and pain may aid our understanding of breast pain.

The aims of this study are as follows:

1. To quantify bare-breasted skin strain magnitude and rates during static and dynamic activity.

2. To identify the effects of breast support garments on breast skin strain, rates and locations of peaks.

3. To investigate the relationships of breast skin strain/ strain rates with nipple kinematics, breast pain and participant characteristics.

\section{METHODS}

\section{Study population and study protocol}

Following institutional ethical approval, 39 women gave written informed consent to participate. However, participants were not involved in the study design, reporting or dissemination of this research. Participants were (mean and range) aged 25 years (19-38 years) with a body mass of $66 \mathrm{~kg}(52-95 \mathrm{~kg})$, nulliparous, had not undergone breast surgery and had not experienced $>15$ min of ultraviolet radiation to the breasts in the last 3 months. ${ }^{35}$ Participants had their bra size assessed by a trained bra fitter, using best-fit criteria ${ }^{36}$ (mode 34B (range 32C to $36 \mathrm{G}$ )), and their underband (mean $80 \mathrm{~cm}$, (range $70-93 \mathrm{~cm}$ ) ) and bust circumference (mean $94 \mathrm{~cm}$, (range $84-109 \mathrm{~cm})$ ) measurements were recorded. A $6 \mathrm{~s}$ barebreasted torso surface scan estimated left breast volume (3D scanner, SizeStream, V.5.2.3) using SizeStream Studio software (V.5.2.3), giving a mean of $728 \mathrm{~mL}$ (range 226-1506 mL)). ${ }^{37}$

Breast and torso positional data were recorded using an electromagnetic $(240 \mathrm{~Hz}$, Liberty, Polhemus, USA) 14-sensor array (mass $<1 \mathrm{~g}$ ) covering participants' left breast, based on rectangular breast segmentation ${ }^{38}$

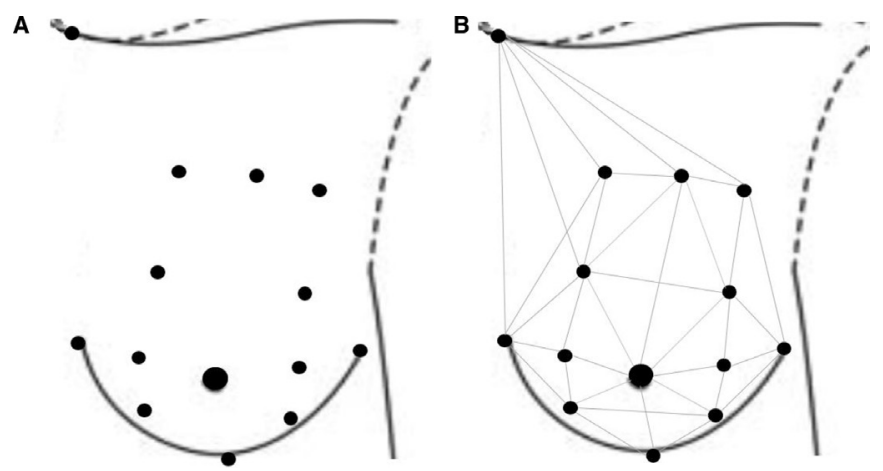

Figure 1 (A) The 14-sensor array (black circles) used to measure breast position. (B) The 35 strain lines identified utilising this array. ${ }^{39}$

(figure 1A). ${ }^{39}$ Two additional sensors on $\mathrm{C} 7$ and $\mathrm{T} 8$ quantified breast motion relative to the torso. ${ }^{40}$

Static sensor coordinates were recorded for $10 \mathrm{~s}$ with the participant in the anatomical position. Following a warm up, dynamic sensor coordinates were recorded during treadmill $(\mathrm{h} / \mathrm{p} / \operatorname{cosmos}$ mercury, NussdorfTraunstein, Germany) walking $\left(1.4 \mathrm{~m} \cdot \mathrm{s}^{-1}, 5.0 \mathrm{~km} \cdot \mathrm{h}^{-1}\right)^{7}$ and running $\left(2.8 \mathrm{~m} \cdot \mathrm{s}^{-1}, 10.0 \mathrm{~km} \cdot \mathrm{h}^{-1}\right)^{7}$ for $30 \mathrm{~s} .{ }^{41}$ Participants performed standing, walking and running in three breast support conditions, no support (barebreasted), low support (an everyday bra used in previous research ${ }^{8}$ ): Marks \& Spencer T-shirt bra, 92\% cotton, $8 \%$ elastane lycra) and high support (a sports bra similar to that used in previous research ${ }^{42}$ ); Shock Absorber Run Bra, $81 \%$ polyamide, $10 \%$ polyester, $9 \%$ elastane). Following walking and running, participants rated their breast pain from 'no pain' 0 to 'worst pain possible' 10 , on a $10 \mathrm{~cm}$ Visual Analogue Scale. ${ }^{43}$ Order of the bra conditions was randomised; however, the no support condition was performed last to prevent residual breast pain from bare-breasted running effecting breast pain scores.

Strain calculation requires the determination of a neutral position (zero strain). The neutral breast position was estimated following the Mills $e t a t^{45}$ methods. Briefly, participants were submerged in water, in an upright, stationary position and sensor coordinates recorded for $10 \mathrm{~s}$. While Mills et at $t^{45}$ used soybean oil and water immersion to estimate the neutral position, water alone identified the neutral position to within $5.6 \mathrm{~mm}$.

\section{Strain, strain rate and nipple kinematics calculation}

Sensor coordinates were exported to Visual 3D (V.4.96.4, C-motion) and filtered (generalised cross-validatory quintic spline).$^{31}$ A reference torso segment was created, with the proximal end (origin) midway between suprasternal notch and C7 sensors, and the distal end midway between xiphoid process and T8 sensors. ${ }^{40}$ Thirty-five inter-sensor distances were calculated for each participant, in each condition (water immersion, standing, walking and running) (figure 1B). 
Static and dynamic breast skin strains were then calculated using

$$
\begin{gathered}
\operatorname{Ext}(\mathrm{m})=\mathrm{L}-\mathrm{L}_{\mathrm{O}} \\
\text { Strain }(\%)=100 .\left(\frac{\mathrm{Ext}}{\mathrm{L}_{0}}\right)
\end{gathered}
$$

and instantaneous dynamic breast skin strain rates,

$$
\text { Strain rate }\left(\% . \mathrm{s}^{-1}\right)=\frac{\Delta \mathrm{Strain}(\%)}{\Delta t}
$$

where $L$ was the inter-sensor distance during any activity at each time point, $L_{0}$ was the mean inter-sensor distance during water immersion (10s) and $t$ was time.

Walking and running gait cycles were identified using every other minima in the vertical suprasternal notch coordinates, and 20 gait cycles were analysed. ${ }^{46}$ Maximum breast skin strain and strain rate, for each strain line, were identified in each gait cycle. The mean maxima was identified for 20 gait cycles and the maximum values across any strain line were selected for each participant (peak strain). Nipple kinematics (range of motion (ROM) $(\mathrm{m})$, peak velocity $\left(\mathrm{m} \cdot \mathrm{s}^{-1}\right)$ and peak acceleration $\left.\left(\mathrm{m} \cdot \mathrm{s}^{-2}\right)\right)$ were calculated relative to the torso coordinate system, ${ }^{47}$ within the same gait cycles.

\section{Statistical analyses}

Using SPSS (V.24), data were checked for normality; 86 out of 111 variables that were not normally distributed (Shapiro-Wilk, $\mathrm{p}<0.05$ ) were compared across no, low and high breast support conditions using Friedman tests, followed by Wilcoxon tests. Where variables were normally distributed (25 variables), data were compared using one-way repeated measures analysis of variance, followed by pairwise post hoc tests with a Bonferroni corrected significance level of $p=0.0167$. Effect sizes were also identified (parametric: $d$, non-parametric: $\mathrm{r}$ ) (weak $<0.3$, moderate $0.3-0.5$, strong $>0.5){ }^{48}$ To investigate relationships of peak breast skin strain/strain rate with nipple kinematics, breast pain and participant characteristics, Pearson's correlations ( $\mathrm{r}$ ) were calculated; trivial $(<0.3)$, low $(0.3-0.5)$, moderate $(0.5-0.7)$, high $(0.7-0.9)$ and very high $(>0.9) .{ }^{49}$ Prior to conducting the correlation analysis, all peak velocities and accelerations were converted to positive values to ensure positive and negative relationships could be identified.

\section{Patient and public involvement}

Patients and/or the public were not involved in the design, or conduct, or reporting or dissemination plans of this research.

\section{RESULTS}

\section{Bare-breasted skin strain magnitudes and rates}

Bare-breasted peak breast skin strain significantly increased from standing (31\%) to walking (36\%) to running (46\%), with all activities displaying mean peak breast skin strain below the potentially damaging

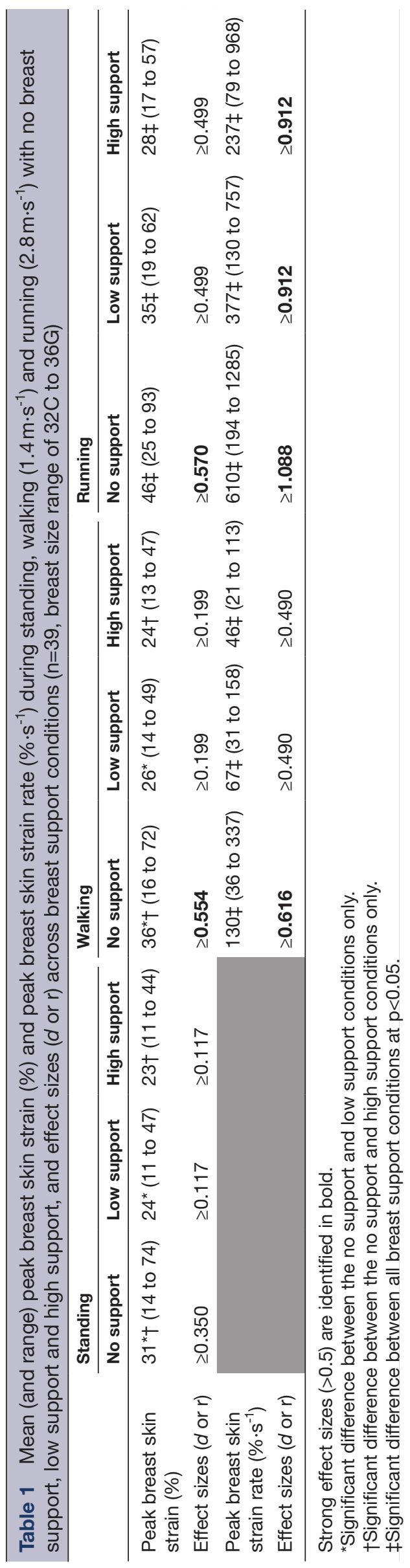



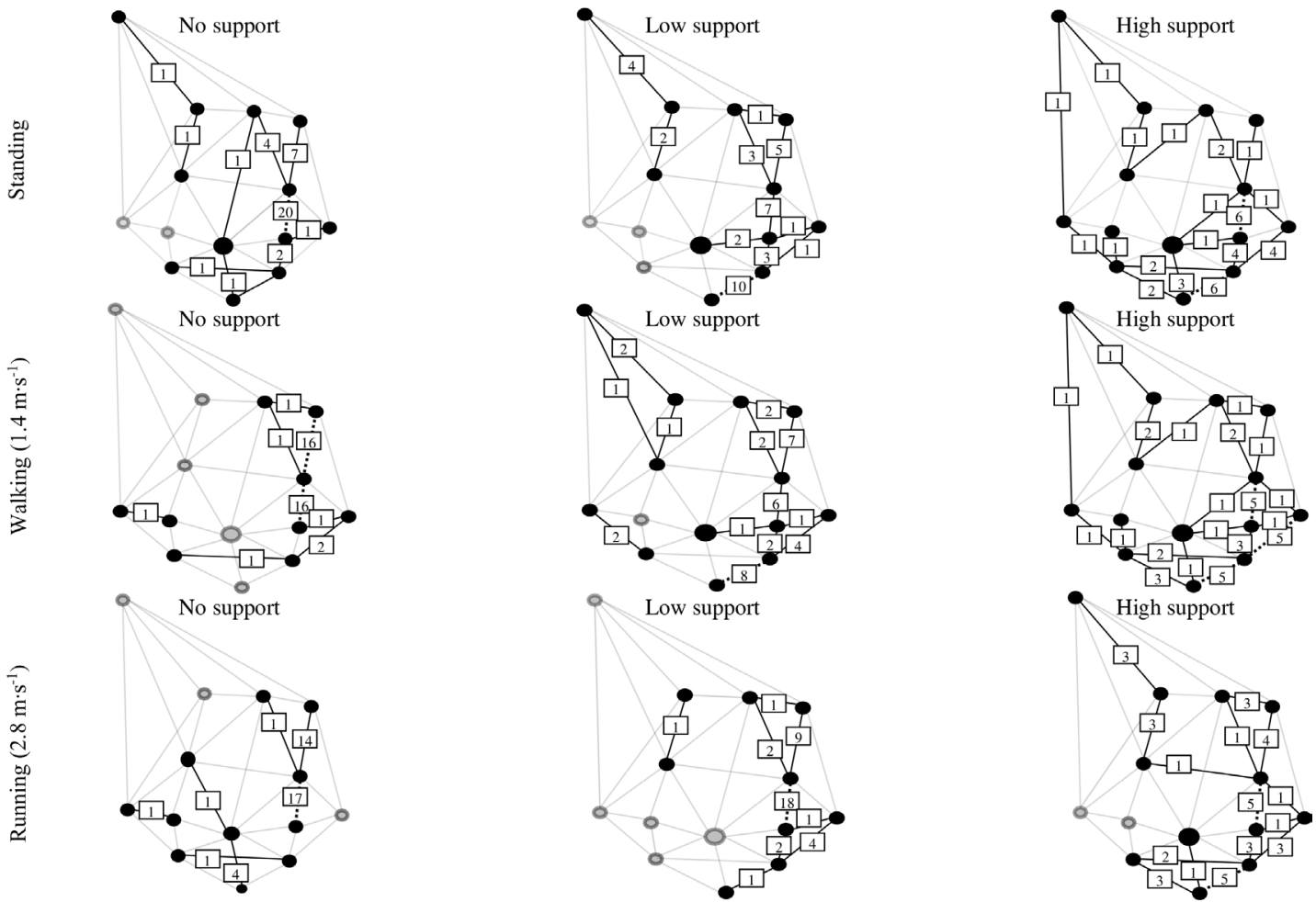

Figure 2 The number of participants who experienced peak breast skin strain in this location, during standing, walking $\left(1.4 \mathrm{~m} \cdot \mathrm{s}^{-1}\right)$ and running $\left(2.8 \mathrm{~m} \cdot \mathrm{s}^{-1}\right)$ in no support, low support and high support conditions $(\mathrm{n}=39$, breast size range of $32 \mathrm{C}$ to 36G). The peak breast skin strain line(s) most prevalent across participants is indicated by a dotted line.

threshold of $60 \%$ (table 1 and online supplementary table 1). However, three participants experienced breast skin strain of greater than $60 \%$ during standing $(62 \%$, $72 \%$ and $74 \%)$ and walking $(70 \%, 70 \%$ and $72 \%)$, while seven participants experienced breast skin strain of greater than $60 \%$ during running $(61 \%-93 \%)$. While peak breast skin strain displayed a moderate increase from walking $(36 \%)$ to running $(46 \%)$, peak breast skin strain rate increased greater than fourfold from walking $\left(131 \% \cdot \mathrm{s}^{-1}\right)$ to running $\left(610 \% \cdot \mathrm{s}^{-1}\right)$.

\section{Effects of breast support on skin strain/strain rate}

Compared with no support, low and high breast support significantly reduced peak breast skin strain across all activities (table 1). However, in low support, one participant displayed peak breast skin strain of $62 \%$ during running. In comparison, in high support, no peak breast skin strains greater than $60 \%$ were identified. Low and high breast support also significantly reduced peak breast skin strain rate, compared with no support, with strong effect sizes. The greatest mean peak breast skin strain rate identified was $610 \% \cdot \mathrm{s}^{-1}$ during running in no support, which was almost three times that displayed when running in high breast support $\left(237 \% \cdot \mathrm{s}^{-1}\right)$.

\section{Breast skin strain profiles}

An increase in breast support resulted in a more diverse distribution of peak strain across the breast (figure 2). The number of participants with a similar location for peak breast skin strain decreased from 20 (no support) to 10 (low support) to 6 (high support) in standing, and 16 (no support) to 8 (low support) to 5 (high support) in walking. In running, the distribution of peak breast skin strain was relatively similar for no support and low support, with most participants displaying peak strain in the lateral breast region.

Peak breast skin strain rate profiles were more homogeneous than the strain profiles, with the majority of participants experiencing peak breast skin strain rate in one location; upper, lateral breast region (figure 3). An increase in breast support during running reduced the number of participants experiencing peak strain rates in the upper, lateral breast region (35 participants in no support and 24 participants in low support). In high support during running, $66 \%$ of participants (26 out of 39 participants) experienced peak strain rates in the medial breast region, suggesting a medial shift in peak breast skin strain rates as these breast support conditions increased.

\section{Relationships of breast skin strain/strain rate with nipple kinematics, breast pain and participant characteristics}

Increased breast support resulted in significant reductions in nipple ROM, velocity and acceleration, in all directions, during both walking and running (table 2), with mostly strong effect sizes $(d$ or $r>0.5)$. As breast support increased, breast pain significantly decreased from 0.75 to 0.37 to 0.13 (out of 10) during walking and from 4.49 to 2.39 to 0.26 during running, with moderate to strong effect sizes. 

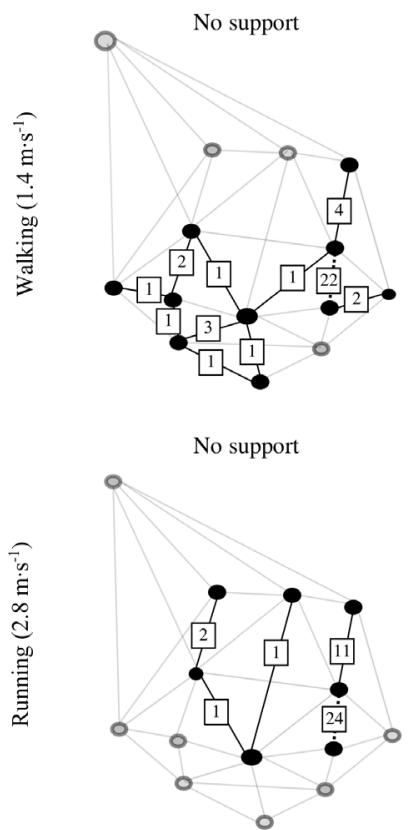
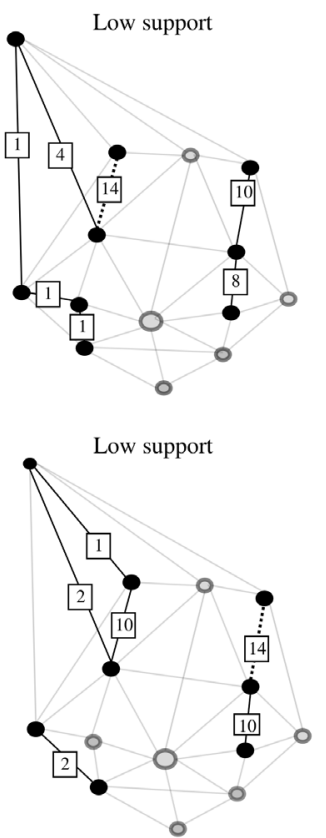

High support

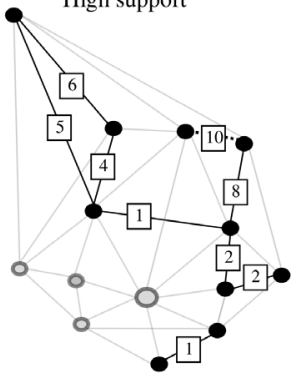

High support

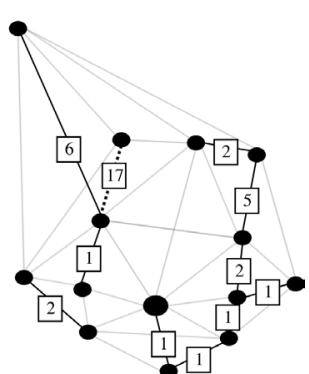

Figure 3 The location of peak breast skin strain rates and the number of participants who experienced peak breast skin strain rates in this location, during walking $\left(1.4 \mathrm{~m} \cdot \mathrm{s}^{-1}\right)$ and running $\left(2.8 \mathrm{~m} \cdot \mathrm{s}^{-1}\right)$ in no support, low support and high support conditions $(n=39$, breast size range of $32 \mathrm{C}$ to $36 \mathrm{G})$. The peak breast skin strain rate line(s) most prevalent across participants is indicated by a dotted line.

When examining the relationships of peak breast skin strain/strain rates with nipple kinematics (table 3), the no support condition demonstrated stronger relationships between strain/strain rate and kinematics and, in general, these relationships reduced as support increased. Compared with walking, running generally displayed stronger relationships between strain/strain rate and nipple kinematics; however, anteroposterior nipple ROM during walking with no support displayed the strongest relationship to peak strain $(\mathrm{r}=0.723)$, while inferior peak nipple acceleration during running displayed the strongest relationship to peak strain rate $(\mathrm{r}=0.891)$. Breast pain displayed weak correlations $(\mathrm{r}<0.5)$ with breast skin strain and strain rate. When examining the relationship of peak breast skin strain/strain rates with participant's physical characteristics, breast volume, body mass index (BMI) and bust circumference displayed moderate to high correlations with strain. Breast volume displayed the strongest correlations (for participant characteristics) to both peak breast skin strain $(\mathrm{r}=0.672)$ and strain rate $(\mathrm{r}=0.705)$.

\section{DISCUSSION}

During static and dynamic activity, this study established bare-breasted skin strain magnitudes and rates, the effect of breast support on strain magnitudes and rates, and where peak strains occurred. Additionally, this study identified the relationships of breast skin strain magnitudes and rates with nipple kinematics, breast pain and participant characteristics.

\section{Breast support levels and peak breast skin strain/strain rate}

The results showed peak bare-breasted skin strain during standing ranged from $14 \%$ to $74 \%$ across participants, similar to values reported by Sanchez et $a \ell^{31}(14 \%-75 \%)$. No conclusive skin strain damage threshold exists, and the $60 \%$ value reported by Silver $e t a l^{26}$ was derived from in-vitro torso and abdomen skin, suggesting caution when applying this threshold to in-vivo breast skin strain assessment. Nevertheless, despite mean peak breast skin strain remaining below $60 \%$ across activities (suggesting low risk of skin damage ${ }^{26}$ ), at least one participant displayed strain values during standing, walking and running in no support ranging from $73 \%$ to $93 \%$, and $62 \%$ during running in low support.

Similar to Haake and Scurr, ${ }^{29}$ peak breast skin strain significantly decreased when running in high support compared with low support. Interestingly, this was not observed during standing and walking; this may be due to the lower intensities of these activities (walking $<5 \operatorname{METs}^{50}$ ), and reduced ROM. ${ }^{79}$ In walking, the low support garment constrained breast skin strain to similar levels as the static condition. Peak breast skin strain rate also significantly decreased when running in high support compared with low support. An increase in skin strain rate has been associated with increased skin stiffness, ${ }^{51}$ which is a prominent factor in soft tissue failure. ${ }^{52}$ The use of breast support during running may therefore decrease participants' risk of breast skin damage due to decreased breast skin strain rates. ${ }^{51}$

Peak breast skin strain in no support was commonly observed longitudinally, in the superior, lateral breast region, similar to Sanchez et al. ${ }^{30}$ While Zhou et a $\tilde{l}^{\tilde{3}}$ 


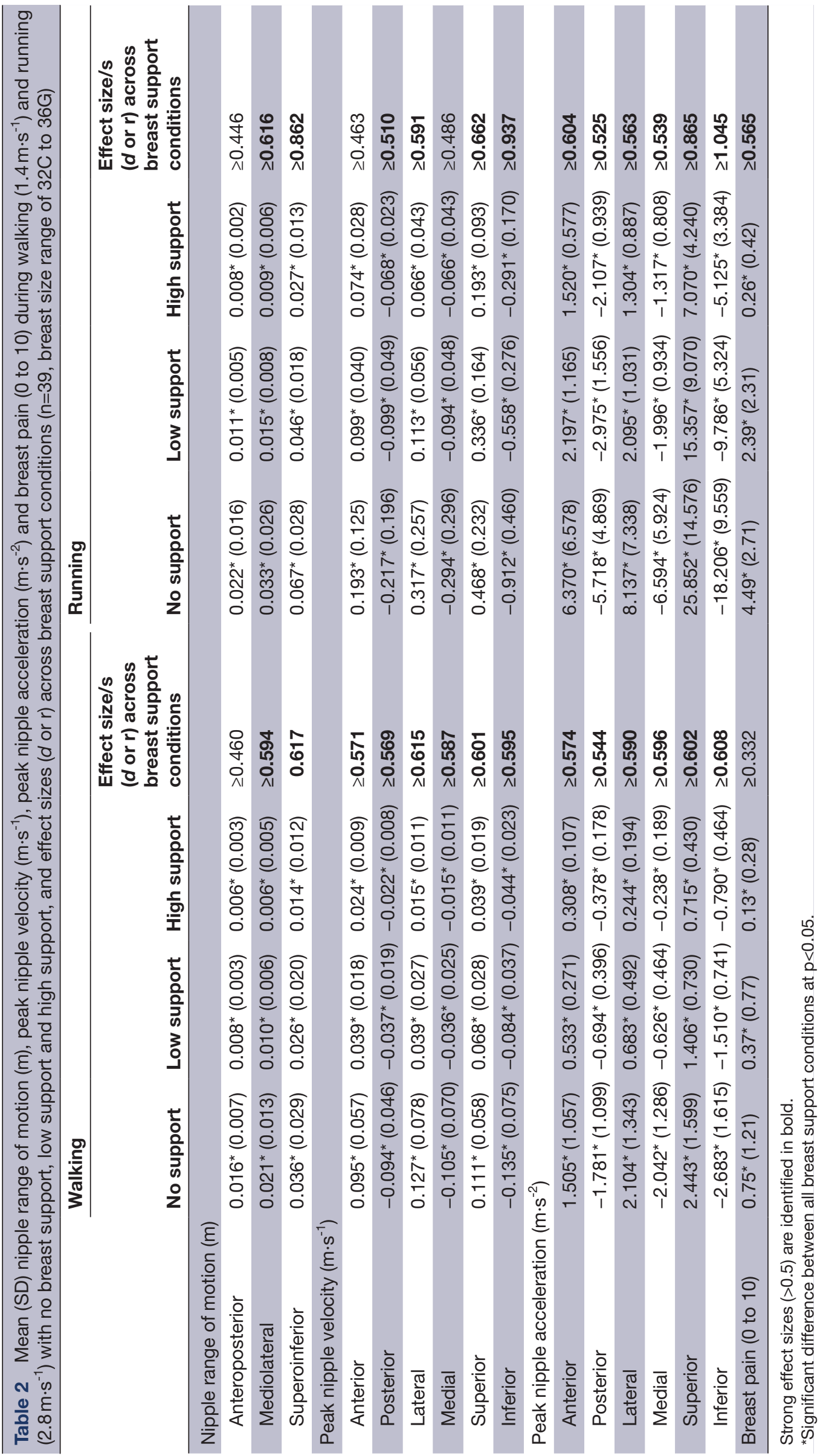




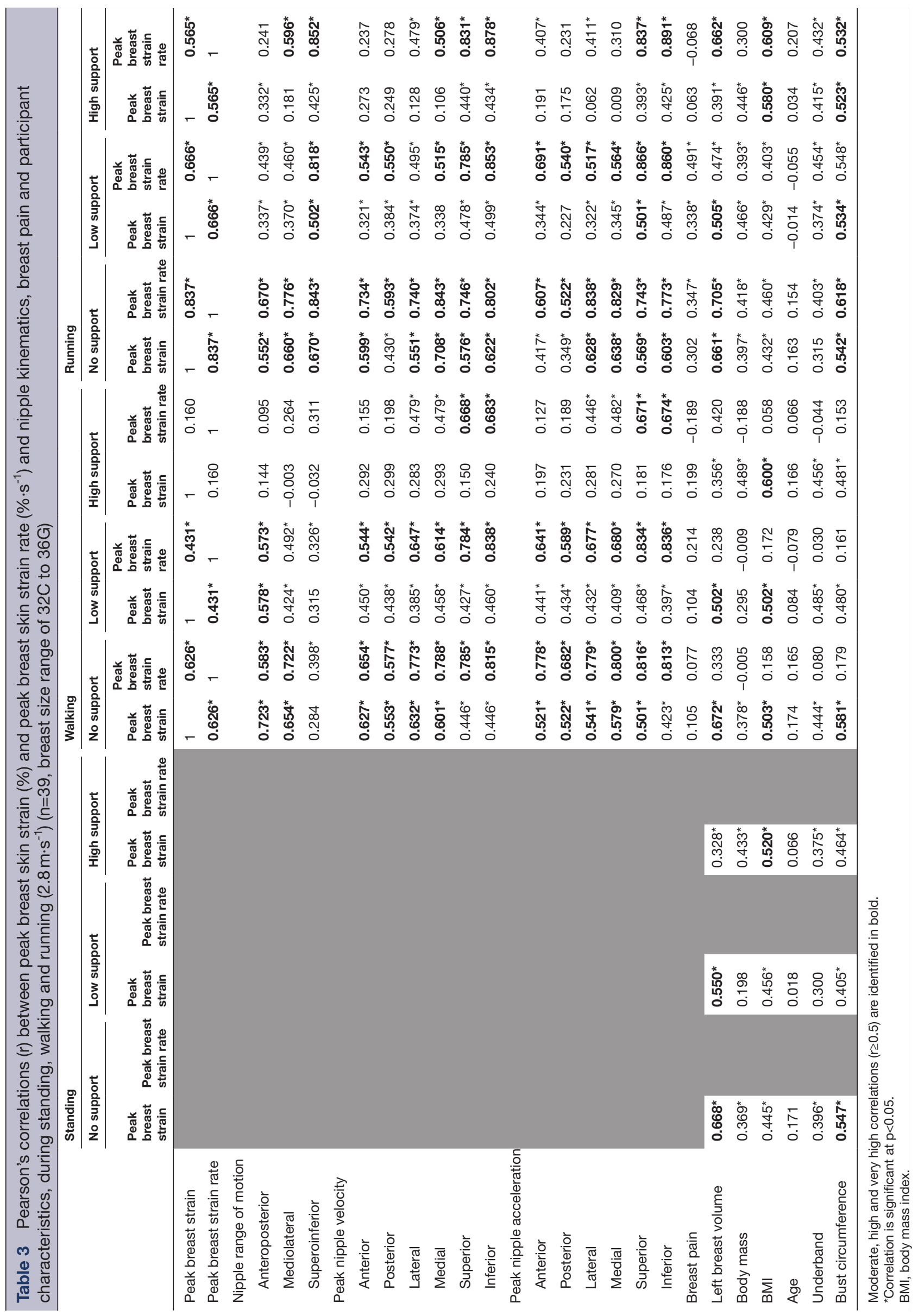


identified the medial, lateral and inferior regions of the breast moved more than the superior region of the breast during bare-breasted running, the current study suggests increased breast support is needed to lift the superior, lateral region of the breast, reducing strain in this region. It must be noted that while peak strain occurs at these locations, they will also achieve their maximum at different instances in time during each gait cycle. Across participants, external breast support resulted in an increased number of locations where peak breast skin strain occurred, suggesting a redistribution of strain which varied across participants. This may be related to the manual positioning of breast tissue inside the bra, which could vary during each bra application and from woman to woman.

Peak breast skin strain rate was also commonly identified longitudinally in the superior breast region, however, in both medial and lateral breast regions. This is supported by the breast Langer lines, ${ }^{54}$ which represent collagen fibre orientation in the skin. ${ }^{55}$ As maximum skin extensibility occurs at right angles to Langer lines, ${ }^{54}$ the most prevalent locations of peak breast skin strain rates within this study (longitudinally in medial and lateral breast regions) may occur at maximum skin extensibility.

\section{Relationships between variables}

All nipple kinematics displayed moderate or high correlations $(r>0.5)$ with peak breast skin strain rate during bare-breasted running. This was interesting but not surprising, as peak breast skin strain rate was not commonly identified on a strain line connected to the nipple, but these results are based on mechanical principles. Further investigation is required to identify whether nipple kinematics could predict breast skin strain magnitudes and rates. Despite previous research reporting associations between skin strain and pain, ${ }^{56-60}$ only weak relationships were observed in this study. This is an important finding from a participant perspective as this suggests that although breast skin strain may not be related to pain, it may still be relevant to skin damage and breast ptosis. ${ }^{16}{ }^{17}$ However, the subjectivity of pain ratings, large SD across participants and very low breast pain ratings during walking $(<0.75$ out of 10$)$ question the sensitivity of the pain scoring system. Considering participant characteristics, breast volume, BMI and bust circumference displayed the strongest and most prevalent relationships with peak breast skin strain/ strain rate. This may in part support Sanchez et $a l^{31}$ who reported that larger breasted women (>34D) displayed increased static breast skin strain (compared with smaller-breasted women). Willson $e t a t^{61}$ identified that breast skin thickness decreased with increased breast size, and thinner skin may be more distensible than thicker skin, ${ }^{62}$ suggesting that women with larger breast volumes may be more susceptible to higher breast skin strain.

\section{Strengths and limitations}

This was the first study to consider breast skin strain rates in vivo. Breast skin strain rate appears to be a valuable measure; when compared with breast skin strain magnitude, strain rate demonstrates consistent differentiation between breast support conditions and activity levels, a more consistent pattern in strain rate location and stronger correlations with nipple kinematics. However, this study is also not without its limitations. While the walking and running speeds of participants were controlled, previous research has identified that individual running styles contribute to breast movement, ${ }^{63}$ with females adopting mechanical alterations to their gait $^{64}$ and trunk displacement ${ }^{65}$ dependent on breast support levels. Future research into breast skin strain/ strain rates should incorporate whole-body kinematic and kinetic analysis which may provide further insight.

\section{CONCLUSION}

This novel study investigated breast skin strain magnitudes and rates during static and dynamic activity. For most participants, breast skin strain was below $60 \%$ during standing, walking and running, suggesting reduced risk of breast skin damage. However, during running, one participant exhibited skin strains up to $93 \%$ in no support and $62 \%$ in low support, coupled with increased strain rates suggesting an increased risk of breast skin damage is possible for some women. Interestingly, when compared with low support, high support did not further reduce breast skin strain during standing and walking, questioning the need for high support during these activities. The location of breast skin strain/strain rate was longitudinal, in the lateral and medial strain lines, suggesting lift is required in these regions to reduce breast skin strain risk. Contrary to previous literature, only weak correlations were observed between breast skin strain/strain rates and breast pain, suggesting that, although breast skin strain may not be related to pain, it may still be relevant to skin damage. Breast skin strain/strain rates were correlated with breast volume, suggesting that women with larger breast volumes may be more susceptible to breast skin strain.

Acknowledgements The authors declare that the results of this study are presented clearly, honestly and without fabrication, falsification or inappropriate data manipulation.

Contributors All coauthors are in agreement to be accountable for the work presented in this manuscript. All authors were involved in the conception and design of this study and the interpretation of data. MN was responsible for initial writing and drafting of the manuscript, which was reviewed by all authors. All authors approved the final version to be submitted.

Funding This work was supported, in part, by the Science Foundation Ireland grant 13/RC/2094 and has received funding from the European Union's Horizon 2020 research and innovation programme under the Marie Skłodowska-Curie grant agreement No. 754489. MN and AS have also received funding for the current study from Hanes Brands. For the remaining authors, none were declared. The results of the present study do not constitute endorsement by ACSM.

Competing interests This work was supported, in part, by the Science Foundation Ireland grant 13/RC/2094 and has received funding from the European Union's Horizon 2020 research and innovation programme under the Marie Skłodowska- 
Curie grant agreement No. 754489. MN and AS have also received funding for the current study from Hanes Brands. For the remaining authors, none were declared. The results of the present study do not constitute endorsement by ACSM.

Patient consent for publication Not required.

Provenance and peer review Not commissioned; externally peer reviewed.

Data availability statement All data relevant to the study are included in the article or uploaded as supplementary information.

Open access This is an open access article distributed in accordance with the Creative Commons Attribution Non Commercial (CC BY-NC 4.0) license, which permits others to distribute, remix, adapt, build upon this work non-commercially, and license their derivative works on different terms, provided the original work is properly cited, appropriate credit is given, any changes made indicated, and the use is non-commercial. See: http://creativecommons.org/licenses/by-nc/4.0/.

ORCID iD

Chris Mills http://orcid.org/0000-0002-8731-3354

\section{REFERENCES}

1 Haake S, Scurr J. A dynamic model of the breast during exercise. Sports Eng 2010;12:189-97.

2 Risius D, Milligan A, Mills C, et al. Multiplanar breast kinematics during different exercise modalities. Eur J Sport Sci 2015;15:111-7.

3 Nolte K, Burgoyne S, Nolte $\mathrm{H}$, et al. The effectiveness of a range of sports bras in reducing breast displacement during treadmill running and two-step StAR jumping. J Sports Med Phys Fitness 2016;56:1311-7.

4 Page KA, Steele JR. Breast motion and sports brassiere design. Implications for future research. Sports Med 1999;27:205-11.

5 Campbell TE, Munro BJ, Wallace GG, et al. Can fabric sensors monitor breast motion? J Biomech 2007;40:3056-9.

6 Gefen A, Dilmoney B. Mechanics of the normal woman's breast. Technol Health Care 2007;15:259-71.

7 Scurr J, White J, Hedger W. Breast displacement in three dimensions during the walking and running gait cycles. J Appl Biomech 2009;25:322-9.

8 Scurr JC, White JL, Hedger W. Supported and unsupported breast displacement in three dimensions across treadmill activity levels. Sports Sci 2011;29:55-61.

9 Mason BR, Page KA, Fallon K. An analysis of movement and discomfort of the female breast during exercise and the effects of breast support in three cases. J Sci Med Sport 1999;2:134-44.

10 Scurr JC, White JL, Hedger W. The effect of breast support on the kinematics of the breast during the running gait cycle. J Sports Sci 2010;28:1103-9.

11 Brown N, White J, Brasher A, et al. The experience of breast pain (mastalgia) in female runners of the 2012 London marathon and its effect on exercise behaviour. Br J Sports Med 2014;48:320-5.

12 White JL, Scurr JC, Smith NA. The effect of breast support on kinetics during overground running performance. Ergonomics 2009;52:492-8.

13 Burnett E, White J, Scurr J. The influence of the breast on physical activity participation in females. J Phys Act Health 2015;12:588-94.

14 Han L, Hipwell JH, Tanner C, et al. Development of patient-specific biomechanical models for predicting large breast deformation. Phys Med Biol 2012;57:455-72.

15 Kuhlmann M, Fear EC, Ramirez-Serrano A, et al. Mechanical model of the breast for the prediction of deformation during imaging. Med Eng Phys 2013;35:470-8.

16 Devillers C, Piérard-Franchimont C, Schreder A, et al. High resolution skin colorimetry, strain mapping and mechanobiology. Int J Cosmet Sci 2010;32:241-5.

17 Piérard GE, Nizet JL, Adant JP, et al. Tensile properties of relaxed excised skin exhibiting striae distensae. J Med Eng Technol 1999;23:69-72.

18 Gao Z, Desai JP. Estimating zero-strain states of very soft tissue under gravity loading using digital image correlation. Med Image Anal 2010;14:126-37.

19 Hull ML, Berns GS, Varma H, et al. Strain in the medial collatera ligament of the human knee under single and combined loads. $J$ Biomech 1996;29:199-206.

$20 \mathrm{Lim} \mathrm{KH}$, Chew CM, Chen PCY, et al. New extensometer to measure in vivo uniaxial mechanical properties of human skin. $J$ Biomech 2008;41:931-6.

21 Miller K. How to test very soft biological tissues in extension? J Biomech 2001;34:651-7.
22 Toms SR, Lemons JE, Bartolucci AA, et al. Nonlinear stress-strain behavior of periodontal ligament under orthodontic loading. Am J Orthod Dentofacial Orthop 2002;122:174-9.

23 Hendriks FM, Brokken D, van Eemeren JTWM, et al. A numericalexperimental method to characterize the non-linear mechanical behaviour of human skin. Skin Res Technol 2003;9:274-83.

24 Venus M, Waterman J, McNab I. Basic physiology of the skin. Surgery 2010;28:469-72.

25 Aziz J, Shezali H, Radzi Z, et al. Molecular mechanisms of stressresponsive changes in collagen and elastin networks in skin. Skin Pharmacol Physiol 2016;29:190-203.

26 Silver FH, Freeman JW, DeVore D. Viscoelastic properties of human skin and processed dermis. Skin Res Technol 2001;7:18-23.

27 Silver FH, Christiansen DL, Snowhill PB, et al. Role of storage on changes in the mechanical properties of tendon and self-assembled collagen fibers. Connect Tissue Res 2000;41:155-64.

28 Kumaraswamy N, Khatam H, Reece GP, et al. Mechanical response of human female breast skin under uniaxial stretching. J Mech Behav Biomed Mater 2017;74:164-75

29 Haake S, Scurr J. A method to estimate strain in the breast during exercise. Sports Eng 2011;14:49-56.

30 Haake S, Milligan A, Scurr J. Can measures of strain and acceleration be used to predict breast discomfort during running? Proceedings of the IMechE 2013;227:209-16.

31 Sanchez A, Mills C, Haake S, et al. Quantification of gravity-induced skin strain across the breast surface. Clin Biomech 2017;50:47-55.

32 Ottenio M, Tran D, Ní Annaidh A, et al. Strain rate and anisotropy effects on the tensile failure characteristics of human skin. J Mech Behav Biomed Mater 2015;41:241-50.

33 Liu F, Li C, Liu S, et al. Effect of viscoelasticity on skin pain sensation. Theor Appl Mech Lett 2015;5:222-6.

34 Liu Z, Yeung K. The preconditioning and stress relaxation of skin tissue. J Biomed Pharm Eng 2008;2:22-8.

35 Fisher GJ, Voorhees JJ. Molecular mechanisms of photoaging and its prevention by retinoic acid: ultraviolet irradiation induces MAP kinase signal transduction cascades that induce AP-1-regulated matrix metalloproteinases that degrade human skin in vivo. $J$ Investig Dermatol Symp Proc 1998;3:61-8.

36 White J, Scurr J. Evaluation of professional Bra fitting criteria for Bra selection and fitting in the UK. Ergonomics 2012;55:704-11.

37 McGhee DE, Power BM, Steele JR. Does deep water running reduce exercise-induced breast discomfort? Br J Sports Med 2007;41:879-83

38 Rajagopal V, Lee A, Chung J-H, et al. Creating individual-specific biomechanical models of the breast for medical image analysis. Acad Radiol 2008;15:1425-36.

39 Norris M, Sanchez A, Mills C, et al. Breast skin strain sensor array configurations. In: 8th World Congress of Biomechanics, 2018: 1045

40 Mills C, Loveridge A, Milligan A, et al. Trunk marker sets and the subsequent calculation of trunk and breast kinematics during treadmill running. Textile Research Journal 2016;86:1128-36.

41 Riley PO, Dicharry J, Franz J, et al. A kinematics and kinetic comparison of overground and treadmill running. Med Sci Sports Exerc 2008;40:1093-100.

42 Milligan A, Mills C, Corbett J, et al. Magnitude of multiplanar breast kinematics differs depending upon run distance. J Sports Sci 2015;33:2025-34.

43 Bijur PE, Silver W, Gallagher EJ. Reliability of the visual analog scale for measurement of acute pain. Acad Emerg Med 2001;8:1153-7.

44 Lau WY, Muthalib M, Nosaka K. Visual analog scale and pressure pain threshold for delayed onset muscle soreness assessment. $J$ Musculoskelet Pain 2013;21:320-6.

45 Mills C, Sanchez A, Scurr J. Estimating the gravity induced three dimensional deformation of the breast. J Biomech 2016;49:4134-7.

46 Place N, Lepers R, Deley G, et al. Time course of neuromuscular alterations during a prolonged running exercise. Med Sci Sports Exerc 2004;36:1347-56.

47 Wu G, van der Helm FCT, Veeger HEJD, et al. ISB recommendation on definitions of joint coordinate systems of various joints for the reporting of human joint motion--Part II: shoulder, elbow, wrist and hand. J Biomech 2005;38:981-92.

48 Field A, Miles J, Field Z. Discovering statistics using IBM SPSS statistics. London, England: Sage Publications, 2013.

49 Hinkle DE, Wiersma W, Jurs SG. Applied statistics for the behavioral sciences. Michigan, U.S.A.: Houghton Mifflin, 1990.

50 Ainsworth BE, Haskell WL, Whitt MC, et al. Compendium of physical activities: an update of activity codes and Met intensities. Med Sci Sports Exerc 2000;32:S498-516.

51 Zhou B, Xu F, Chen CQ, et al. Strain rate sensitivity of skin tissue under thermomechanical loading. Philos Trans A Math Phys Eng Sci 2010;368:679-90. 
52 Joodaki H, Panzer MB. Skin mechanical properties and modeling: a review. Proc Inst Mech Eng H 2018;232:323-43.

53 Zhou J, Yu W, Ng S-P. Studies of three-dimensional trajectories of breast movement for better Bra design. Textile Research Journal 2012;82:242-54.

54 Gibson T, Stark H, Evans JH. Directional variation in extensibility of human skin in vivo. J Biomech 1969;2:201-4.

$55 \mathrm{Xu} \mathrm{F,} \mathrm{TJ} \mathrm{L.} \mathrm{Introduction} \mathrm{to} \mathrm{skin} \mathrm{Biothermomechanics} \mathrm{and} \mathrm{thermal}$ pain. Beijing, China: Science Press, 2011.

56 Hirsch C, Ingelmark B-E, Miller M. The anatomical basis for low back pain. Studies on the presence of sensory nerve endings in ligamentous, capsular and intervertebral disc structures in the human lumbar spine. Acta Orthop Scand 1963;33:1-17.

57 Markolf KL, Schmalzried TP, Ferkel RD. Torsional strength of the ankle in vitro. The supination-external-rotation injury. Clin Orthop Relat Res 1989;246:266-72.

58 Micheli LJ, Wood R. Back pain in young athletes. significant differences from adults in causes and patterns. Arch Pediatr Adolesc Med 1995;149:15-18.
59 Moore J, Kennedy S. Causes of chronic pelvic pain. Best Pract Res Clin Obstet Gynaecol 2000;14:389-402.

60 Quinn KP, Lee KE, Ahaghotu CC, et al. Structural changes in the cervical facet capsular ligament: potential contributions to pain following subfailure loading. Stapp Car Crash J 2007;51:169-87.

61 Willson SA, Adam EJ, Tucker AK. Patterns of breast skin thickness in normal mammograms. Clin Radiol 1982;33:691-3.

62 Hussain SH, Limthongkul B, Humphreys TR, et al. The biomechanical properties of the skin. Dermatologic Surgery 2013;39:193-203.

63 White J, Mills C, Ball N, et al. The effect of breast support and breast pain on upper-extremity kinematics during running: implications for females with large breasts. J Sports Sci 2015;33:2043-50.

64 Shivitz NL. Adaptation of vertical ground reaction force due to changes in breast support in running. Oregon State University, 2001.

65 Boschma AC, Smith GA, Lawson L. Breast support for the active woman: relationship to 3D kinematics of running. Med Sci Sport Exerc 1994. 